\title{
Mass action models of Falklands War battles
}

\author{
B. M. Pincombe ${ }^{1}$ \\ A. H. Pincombe ${ }^{2}$
}

(Received 9 January 2016; revised 3 October 2016)

\begin{abstract}
We develop a dataset describing variables associated with six Falklands War battles: combatant numbers; deaths; temporal aspects; and offensive support. Linear relationships between battle duration and deaths necessitate using force and loss ratios to remove temporal variation. Mass action models of battle attrition fit this dataset poorly (at best coefficient of determination $R^{2}=0.10$ ). The low level rules in simulations used by military force designers frequently share assumptions with, or are, mass action models. Errors in force balance or constitution are dangerous so exposing problems with and exploring improvements on existing combat models is important. While six data points are too few for a thorough analysis, our results are consistent with: a linear relationship between time in danger and number killed; different times in danger for the two sides, dependent on detection and lethality ranges; and data substructure, even when temporal aspects are removed
\end{abstract}

DoI:10.21914/anziamj.v57i0.10450, (C) Austral. Mathematical Soc. 2016. Published October 10, 2016, as part of the Proceedings of the 12th Biennial Engineering Mathematics and Applications Conference. ISSN 1445-8810. (Print two pages per sheet of paper.) Copies of this article must not be made otherwise available on the internet; instead link directly to the DOI for this article. Record comments on this article via http://journal austms.org.au/ojs/index.php/ANZIAMJ/comment/add/10450/0 
through ratio models. This data substructure indicates at least one extra variable needs to be considered. We contend that this variable is related to suppression, and this contention is not falsified by the high use of offensive support in the most successful attacks. Mathematical modellers should consider cancelling out temporal variation in combat datasets through ratio models and/or exploring the effects of mutable detection and lethality ranges. Suppression is an attempt to manage exposure to death, to introduce non-stationarity and irregularity into the dataset to benefit the suppressor, to change the bounds of the system using a soft controller; we should investigate how to model it. Force designers should ask simulation modellers whether the mathematical models underlying their simulations represent suppression accurately (or at all) and rethink reductions of simultaneously delivered offensive support available on demand based on models ignoring suppression.

\section{Contents}

1 Introduction

2 Background

C238

3 Results and Discussion

C240

4 Conclusion

C246

References

C248

\section{Introduction}

Mass action models of battle attrition are popular with modellers due to their simplicity. While simplicity is good [14], evidence from battle data shows that such models do not represent battle attrition well $[23,17]$. Similar 
problems in mass action models in other applications were due to the need for further variables beyond population sizes. We develop a dataset based on the six major battles of the Falklands War and test standard mass action models against it. While six datapoints are too few to show a model fits, they are enough to raise serious doubts about a model with a best fit that generates a coefficient of determination $R^{2}=0.10$, which is what we find for mass action models. We present evidence of considerable uncertainty in the time troops actually spent in danger during a battle. Time in danger has an almost linear relation to overall losses, so that uncertainties are passed on to overall attrition. Information on time in danger is available for the Falklands War because it was a small scale, well reported war, but it is unlikely to be available for datasets of large battles. We need models that do not pass on such uncertainties. When both forces suffer identical times in danger, a ratio model (predicting loss ratio from force ratio) can remove the uncertainty [23, 24].

We also present evidence consistent with: suppression by artillery changing the relationship between loss ratio and force ratio in favour of the attackers; slowing of advances though engineering preparation of the battlefield changing the relationship between loss ratio and force ratio in favour of the defenders; and of asymmetry of time in danger for the two forces due to differences in detection and lethality ranges.

In a companion paper [25], we use a mathematical approach to produce a more realistic model consistent with current mass action models of attrition, but taking into account dispersion and variations in detection and lethality ranges. We exhort others to follow the lead of Millikan et al. [18] and attempt to model suppression, as it appears likely that it is either the next variable to add into mathematical models of combat or part of a composite variable based on ability to manoeuvre without being fired upon. 


\section{Background}

Armies have always combined different arms to exploit the weaknesses of their opponents and protect their own vulnerabilities. Classical and medieval armies teamed shock and missile infantry and cavalry to defeat and put enemies to flight. Military engineers were frequently used to adapt the natural landscape to inhibit enemy mobility or to enable manoeuvre. Gunpowder transformed artillery, liberating it from sieges to also join field armies, and, by the middle of the 18th Century, led to the merger of shock and missile infantry producing an infantry, cavalry and artillery package that acted like a macabre game of rock, paper, scissors where moves were open and the challenge was whether you had the capacity to form the paper to wrap your opponent's rock while warding off their scissors.

Advances in the range and rate at which accurate fires could be delivered, accelerating following 1850, meant infantry or cavalry seeking to advance frontally in 1914 faced three orders of magnitude more fire than in the Napoleonic era; technological innovations in fusing and fragment generation also made each artillery round considerably more deadly. Increasing rifle range meant that direct fire artillery, while always maintaining a theoretical range advantage, was frequently inside the range of infantry when they came into view on crowded battlefields. Communications advances, first telephone then radio, allowed artillery to separate observers from guns and introduce indirect fires over intervening topography. The solution to crossing the wide zone of annihilating fires generated by increasing lethality was to use cover, concealment, dispersion, small-unit independent manoeuvre, suppression ${ }^{1}$ and closer combined arms integration [3, 7] across multiple scales so even "the squad [was] a combined arms unit ... capable of combining the actions of different weapons to produce a decisive effect on the enemy" [8].

In the midst of this increasing complexity there were at least five independent

${ }^{1}$ Suppressive fire does not seek to kill but to degrade enemy performance below that necessary to fulfill their mission, usually only for the duration of the fire. 
formulations of mass action models of land combat [6, 9, 2, 15, 19] that, augmented by Peterson [20], is represented in a generalised manner as

$$
\frac{d R}{d t}=-e^{C} B^{G} R^{D}, \quad \frac{d B}{d t}=-e^{F} B^{D} R^{G},
$$

where R and B are the force numbers of the 'red' (enemy) and 'blue' (friendly) sides, respectively, and the exponents $\mathrm{C}$ and $\mathrm{F}$ represent the 'combat power' (i.e., all of the other important factors) of the 'blue' and 'red' forces, respectively. The values of exponents $\mathrm{D}$ and $\mathrm{G}$ define the particular Lanchester model: $\mathrm{D}=0, \mathrm{G}=1$ for the 'direct fire' or 'square law' model $[6,9,2,15,19]$ where the attrition rate for each force is proportional to the number of shooters on the opposing force; $D=1, G=1$ for the 'indirect fire' or 'linear law' model $[15,19]$ where the attrition rate depends on both the number of shooters and the number of targets; and $\mathrm{D}=1, \mathrm{G}=0$ for the 'log law' [20] where the attrition rate for each force is proportional only to the number of that force exposed to combat. In these mass action models, all variables other than force populations are represented by constant coefficients. In a detailed sense, this is unrealistic: coefficients are only constant for short periods over small areas. In an averaged or aggregated sense, constant coefficients imply the assumption that other variables are unimportant.

Armies have settled on a five role breakdown of the combined arms force: infantry; armour; artillery; engineers; and aviation. The increasing fight for electromagnetic supremacy has led some to suggest a combination of communication, detection and electronic warfare, say 'signals', as a sixth role. Models frequently ignore the effects of logistics but modern combat arms carry little of the fuel, water, ammunition and food that they require to function. One of the main roles of combat arms in manoeuvre warfare is to disrupt enemy logistics; the best infantry will not last a day without water and the best tank is useless without fuel or ammunition. This has led some to propose 'cyber', which can strike logistics in a non-kinetic way, as another arm or as a part of a broader signals arm.

Mathematical modellers have responded to combined arms through (situ- 
ational) force scoring and heterogeneous models. Force scoring, initially defining artillery, cavalry and machine guns in terms of "infantry equivalents" [19], attempts to deal with non-homogeneity but misses interaction effects and force employment issues. Situational force scoring seeks to correct some of the employment oversights by scoring a force against its enemy in a terrain, for example tanks are less useful in urban settings than open country or anti-tank weapons do not add much to a force score if the enemy has no tanks. This approach requires enormous numbers of cases to span the space of possibilities and is, essentially, overfitting which makes it very hard to generalise [17]. Linear systems of mass action models with separate force numbers specified for each of the combined arms are commonplace. However, the only interaction effects between the different arms are in their ability to produce casualties in the enemy forces rather than the more important role of combined arms in reducing own force casualties through suppression.

We evaluate mathematical models in the context of the Falklands War, fought between the UK and Argentina in the South Atlantic between 2 April 1982 to 14 June 1982, resulting in the deaths of 649 Argentine combatants, 255 UK combatants and 3 UK civilians; noting that the actual outcomes of the land battles of the Falklands each represent only the realised outcome of many potential outcomes and that any work to design a more effective force, best able to adapt to novel circumstances, needs to consider a much broader set of scenarios than those provided by the Falklands [27, 4, 26].

\section{Results and Discussion}

Our dataset describing the combatant numbers, deaths, temporal aspects and offensive support used in six Falklands War battles was generated from numerous sources $[1,5,10,11,12,13,16,28,29,30]$. In the results presented in Figures 2 and 3 we follow the use of ratio data by Pincombe et al. [24] in response to the data uncertainty identified by Pincombe et al. [23], rather than using an envelope method [21, 22]. Figure 1 shows that the three main 
Figure 1: The square, linear and log laws all assume linear relationships between loss ratio and force ratio, only the slopes differ with a positive slope for the log law, a negative one for the square law, and zero slope for the linear law when $\mathrm{C}=\mathrm{F}=0$ in equation (1).

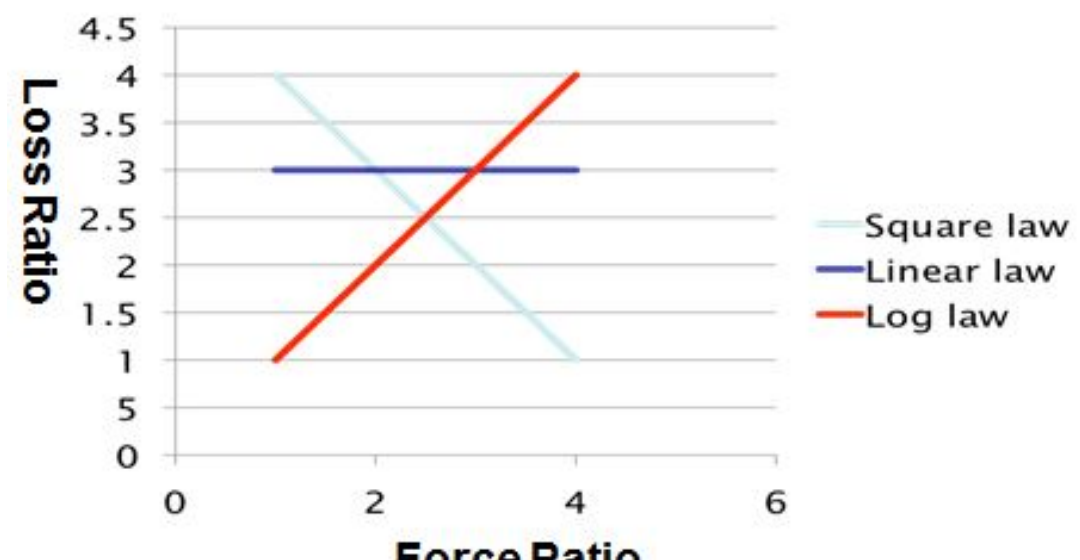

mass action models predict qualitatively different relationships between the force and loss ratios where, in this case, the force ratio is the number of Argentine soldiers involved in the battle divided by the number of UK soldiers involved and the loss ratio is the number of Argentine soldiers killed divided by the number of UK soldiers killed.

The least squares fit for equation 1 applied to the six land battles of the Falklands War is shown in Figure 2. Comparing with Figure 1, a log law dependence is evident but this appears to be unrepresentative of the data substructure implying that this substructure is due to other variables. The sample size is very small but these results are consistent with most of the variance being between battles with high and low offensive support. Figure 2 is consistent with the log law best fit, frequently seen for fits of combat datasets $[23,24,17]$, being an artefact of more voluminous offensive support for a number of battles with slightly less favourable force ratios for the 
Figure 2: The regression line for the best-fit of (Loss Ratio) $=1.07$ (Force Ratio $)^{5.69}$ is graphed with the outcomes of the six battles $\left(R^{2}=0.10\right)$. The two battles above the line of best-fit are Mount Harriet to the left, where 3000 rounds of $105 \mathrm{~mm}$ and 264 rounds of $114 \mathrm{~mm}$ ammunition was fired, and Wireless Ridge to the right, where 6000 rounds of $105 \mathrm{~mm}$ and 476 rounds of $114 \mathrm{~mm}$ ammunition was fired. These were situations with a high level of close support of infantry by indirect fire weapons. Below the line of best fit lie, from left to right, Two Sisters, Tumbledown, Mt Longdon and Goose Green that had lower levels of close support; respectively: $1500105 \mathrm{~mm}$ and $164114 \mathrm{~mm} ; 1500105 \mathrm{~mm}$ and $376114 \mathrm{~mm} ; 1500105 \mathrm{~mm}$ and $156114 \mathrm{~mm}$; and $960105 \mathrm{~mm}$ and $135114 \mathrm{~mm}$.

Falklands land battles

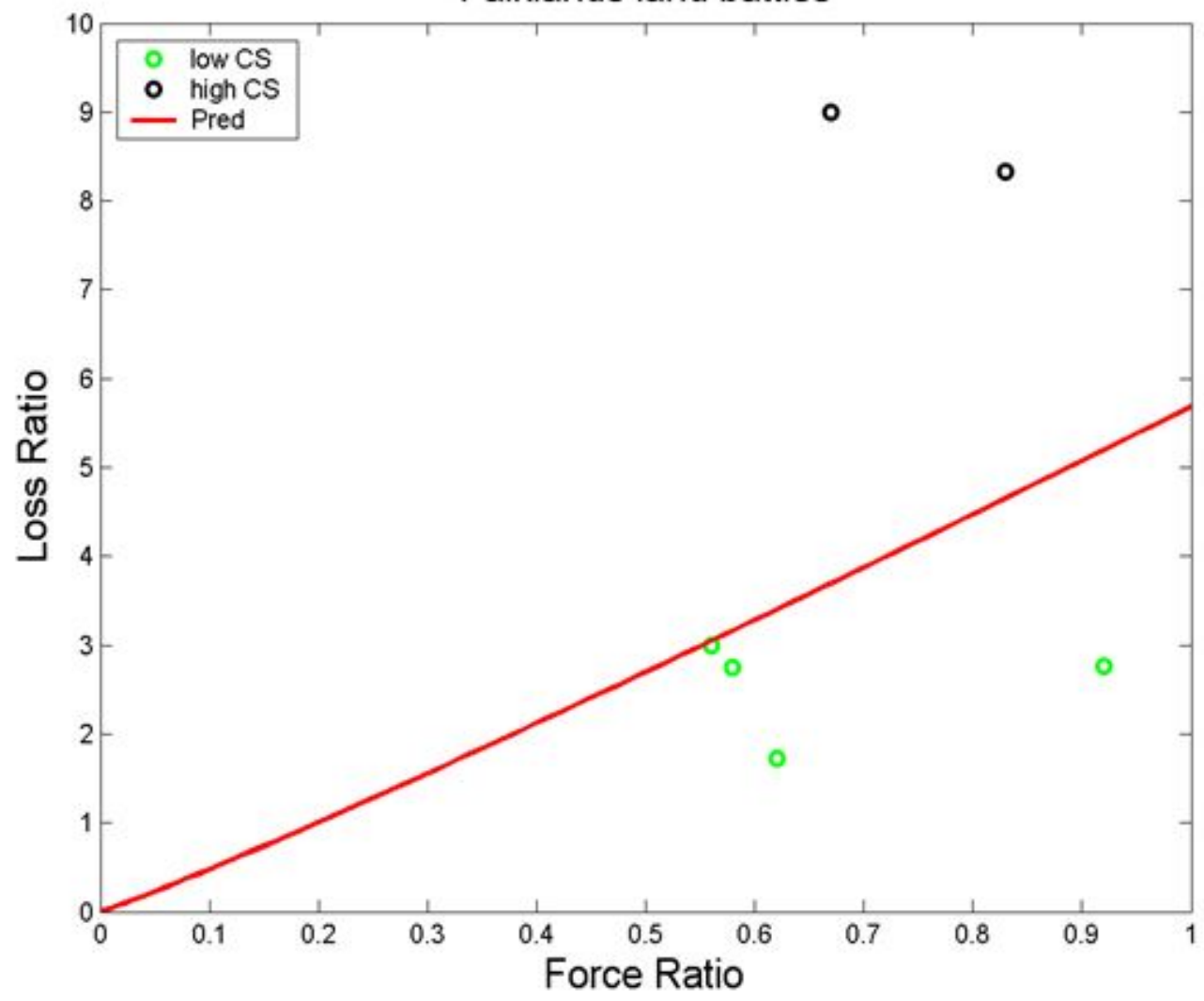


attackers; but the sample size is too small to test this hypothesis.

Information on the battles shown in Figure 3 reveal part of the reason why we classified Mt Harriet and Wireless Ridge as high offensive support battles, the other part is the relatively short time over which these rounds were fired (shown in Figure 4). Although there are few data points the data is consistent with offensive support being an important part of the package that made Mt Harriet and Wireless Ridge high loss ratio battles (i.e., good for the attackers). The difference in loss ratio across the three battles with similar force ratios and total offensive support shows that some other factor must be at play too.

Goose Green is an anomaly in Figures 2 and 3, with the force ratio being different in the two cases. We represent the data in two ways because of the differences in the literature. While we suspect that the source that only counts Argentine forces that fought as infantry as being engaged [12] (and gives the lower figure used in Figures 2) is more consistent with the counting of Argentine troops in other battles (where rear area mechanics and artillery personnel are not counted) we still present the larger and more widely accepted number for Argentine troops [29, 11, 10] in Figure 3. Had this been used in Figures 2 the already poor $R^{2}$ value would be even worse. Goose Green was also spread over a much larger area than the other battles so it was really a series of company level engagements rather than a battalion engagement. Indeed, a significant fraction of the offensive support shown (including all of the $114 \mathrm{~mm}$ fire) was expended on one of these engagements where there were no UK deaths and nine Argentine deaths [12]. Goose Green, as a larger battle, also presents evidence of the importance of manoeuvre in causing defenders to withdraw when threatened with flanking or envelopment [12].

There is a strongly linear relationship in Figure 4 between the time that UK battalions were in combat and the number of casualties experienced by the formation. The UK commitment of a battalion to each battle meant that all battles were fought by roughly the same number of UK troops. The offensive support figures shown in Figure 4 reinforce the degree to which 
Figure 3: Loss ratio is graphed against force ratio. This graph should be interpreted in conjunction with Figure 4 which gives information about how long each battle lasted.

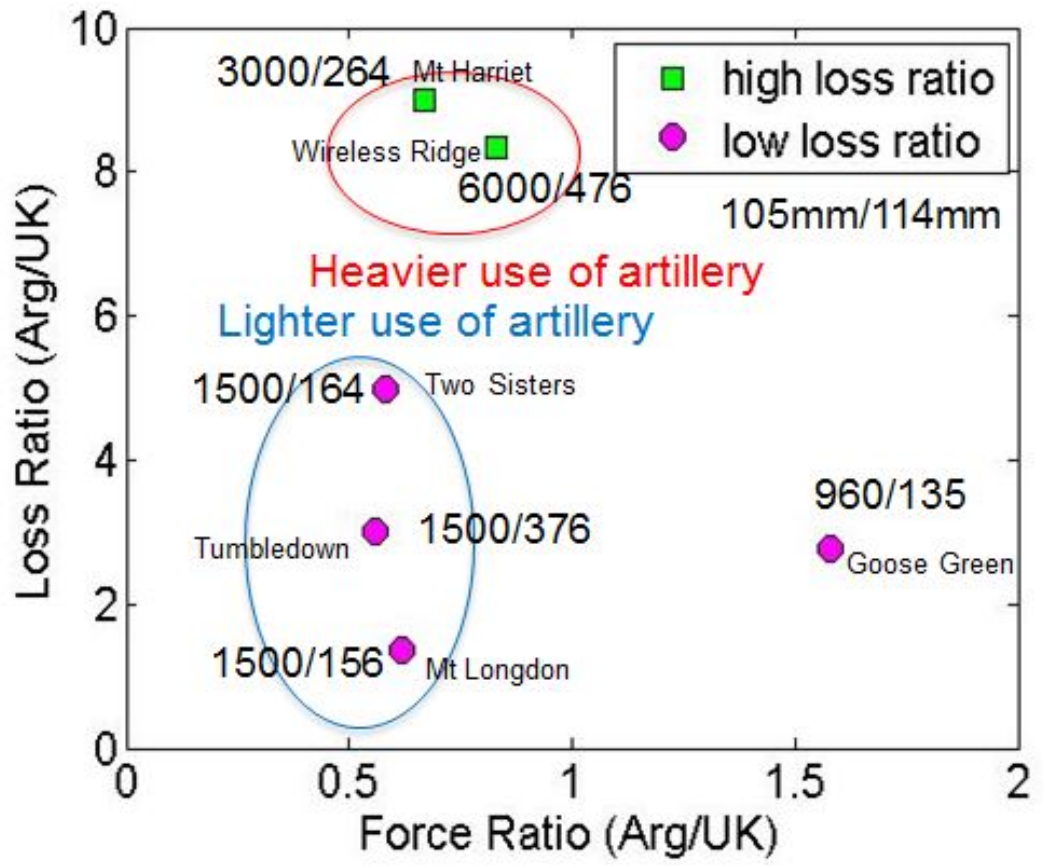

Mt Harriet and Wireless Ridge should be seen as high offensive support battles given the short times over which this large number of rounds was fired. However, Wireless Ridge was a 'noisy' attack so the 6000 rounds of ammunition started to be expended well before the UK troops became engaged, covering their final advance and providing deception for this by preceding it by feint bombardments. The results in Figure 4 are consistent with offensive support providing protection to attackers by speeding up the resolution of the combat; we contend that this is due to the suppressive effects of the fires. These results are also consistent with engineering modifications of the battlefield, such as the mines that were prominent at Tumbledown and Mt Longdon, resulting in higher casualties through slowing down the 
Figure 4: UK losses graphed against hours UK infantry and engineers were engaged in combat for the six major battles of the Falklands War. The number of $105 \mathrm{~mm}$ gun rounds and $114 \mathrm{~mm}$ naval gun rounds fired in support of each operation is shown as are salient details about whether artillery support began before ('noisy attack') or when ('silent attack') Argentine forces detected the attack.

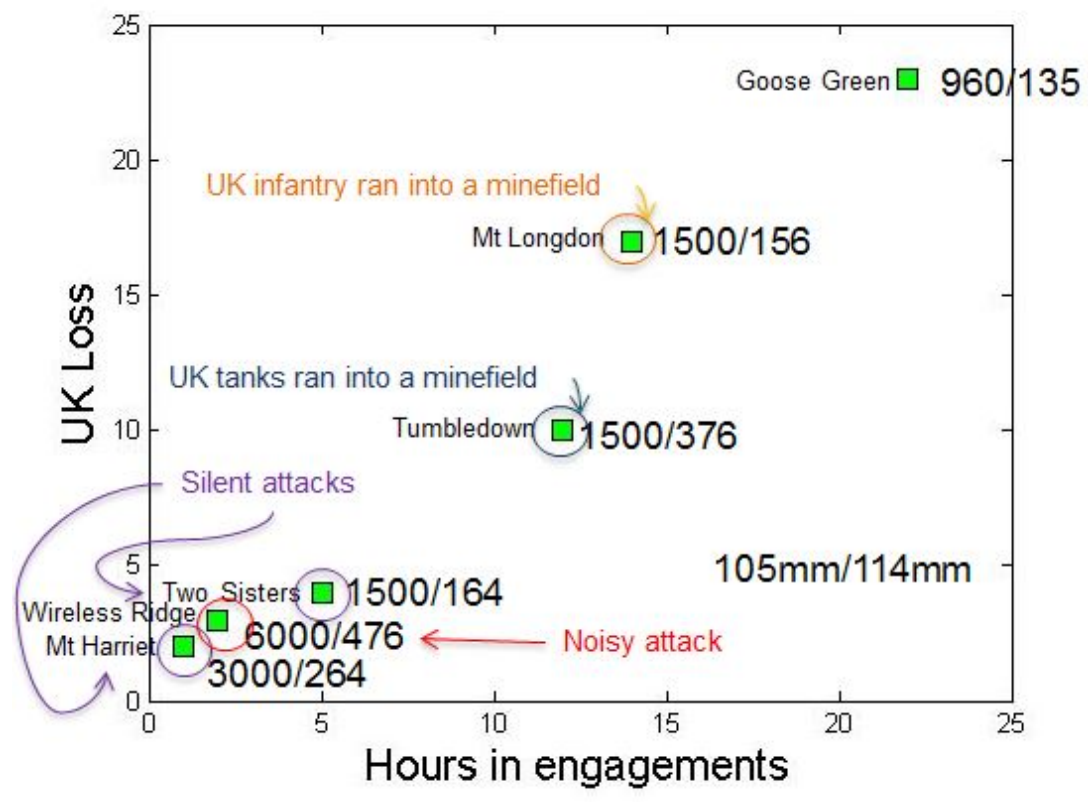

attack and keeping attackers in danger for longer. Unfortunately, given they are such a persistent and undiscriminating weapon, mines also provided the first tipoff to defending forces that they were being attacked at Two Sisters, Tumbledown and Mt Longdon, effectively extending the detection range of Argentine troops.

The temporal dependence of casualty numbers is important. If the time spent in engagements varies from day to day, then the casualty figures in large battle datasets, where the basic time unit is one day, will vary without apparent 
explanation [23]. If the time in engagements is the same for the two forces, then the use of a ratio model, using the state equation formed by integrating equation (1) to generate the loss ratio as a function of the force ratio, removes the uncertainty [24]. The remaining uncertainty is caused by factors which change the relationship between force ratio and loss ratio: factors which are asymmetric. Our investigations are consistent with asymmetries due to the allocations of offensive support and the extra variable that is required may be related to this.

Finally, some words of caution. At most scales a large proportion of casualties can be ascribed to a single mistaken incident and Figure 5 is consistent with this. The mistaken exposure of crowded troopships to Argentine air attack at Bluff Cove led to 56 of the 255 UK deaths in the war. The mistaken exposure of HMS Glamorgan to exocet strike led to 14 UK deaths compared with the eight in the operation it was supporting: Two Sisters. Forces in a position to take advantage of transitory vulnerabilities benefit and their opponents suffer but intelligent people with agency are seeking to generate these vulnerabilities in their enemy and protect themselves. Assuming stationarity and regularity in a control setting assumes the controller is separate from the problem context but numerous Army commanders on both sides are shaping their problem contexts; they are trying to make the distributions of outcomes better for them and, therefore, not stationary or regular.

\section{Conclusion}

We developed a Falklands War battle dataset and showed that the best fitting mass action model of attrition fitted it poorly $\left(R^{2}=0.10\right)$ and did not explain the data substructure, indicating that there is likely to be at least one extra variable needed beyond population size. Our results are consistent with a linear relationship between time in danger and number killed, different times in danger for the two sides, lethality variation depending on detection range and a relationship between offensive support and loss ratios more favourable 
Figure 5: UK deaths are shown for the six battles, the Bluff Cove air attacks and the exocet strike on HMS Glamorgan. The top panel points out that Bluff Cove was one exposure to danger and that UK losses on HMS Glamorgan and at Two Sisters are related. The bottom panel points out that a single aircraft or missile caused most of the casualties in both incidents.

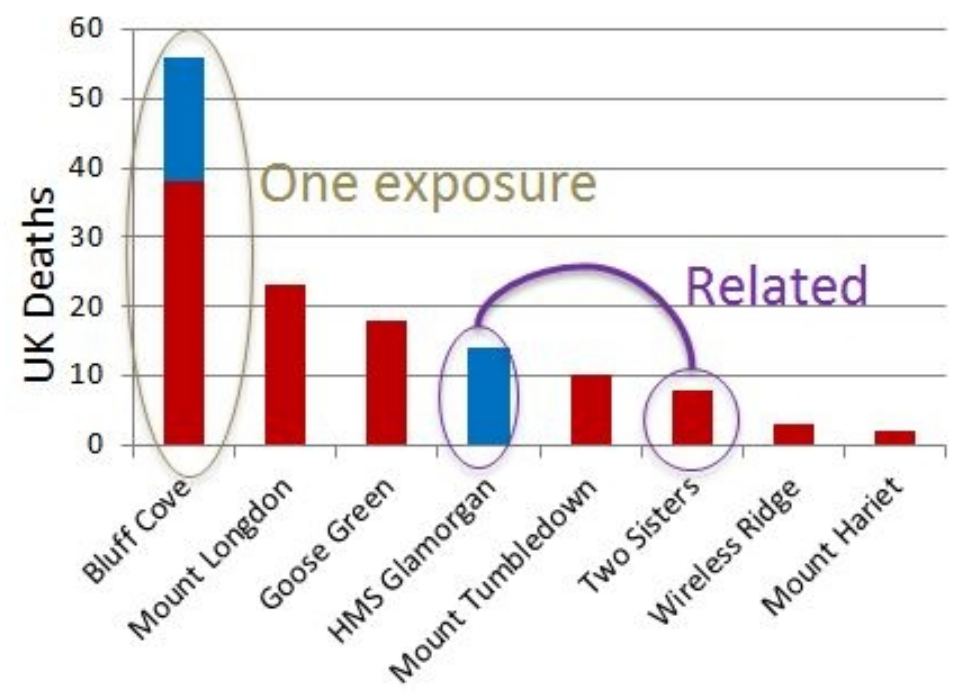

- Sea Force - Land Force
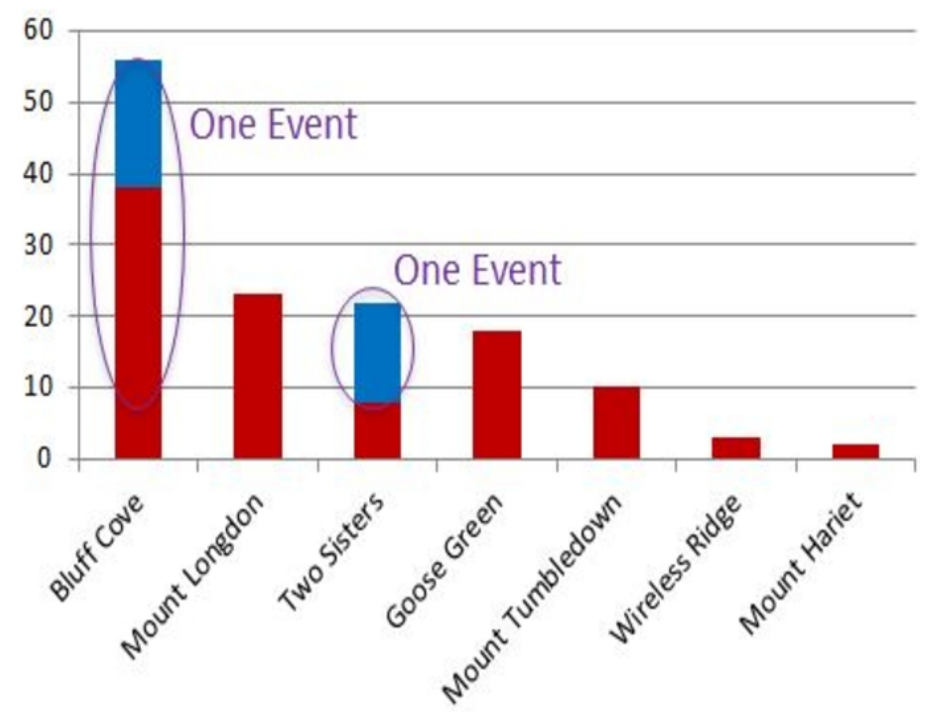
to attackers and manoeuver restriction and loss ratios more favourable to defenders. We contend that the relationship between offensive support and changing loss ratios is mediated through suppression.

Our study could be improved through access to Argentine and UK unit diaries, such as that of HMS Yarmouth [30], rather than secondary sources to give a better idea of timings and volumes of casualties, exposures and fires. We know that UK forces suppressed Argentine artillery [16, 5, 11, 13] and that Argentine artillery still struck at UK infantry $[11,29]$ but the secondary sources available have not yielded data on the timings and volumes of fire involved. Unit diaries may contain this detailed data.

Further work could consider: cancelling out temporal variation in combat datasets through ratio models; investigating the effects of dispersion into small teams and variation in detection and lethality ranges [25]; modelling the effects of suppression; or modelling manoeuvre on the battlefield. Nonmathematical readers who are interested in designing military forces should ask their simulation and modelling experts how they model suppression and manoeuvre.

\section{References}

[1] J. B. A. Bailey. Field artillery and firepower. Routledge, London, 2009. $\mathrm{C} 240$

[2] A. Baudry. La Bataille navale: études sur les facteurs tactiques. 1912. Translated by C. F. Atkinson. The naval battle: Studies of the tactical factors. Hugh Rees, London, 1914.

http://gallica.bnf.fr/ark:/12148/bpt6k11639411/f9.image $\mathrm{C} 239$

[3] S. Biddle. Military power: Explaining victory and defeat in modern battle. Princeton University Press, Princeton, New Jersey, 2004. C238 
[4] F. D. J. Bowden, B. M. Pincombe and P. B. Williams. Feasible scenario spaces: A new way of measuring capability impacts. In T. Weber, M. J. McPhee and R. S. Anderssen (eds), MODSIM2015, 836-842, 2015. http://www.mssanz.org.au/modsim2015/D3/bowden.pdf C240

[5] D. Brown. The Royal Navy and the Falklands War. Pen and Sword Books, Barnsley, UK, 1987. C240, C248

[6] J. V. Chase. Sea fights: A mathematical investigation of the effect of superiority of force in combats upon the sea. Naval War College Archives, RG 8, Box 109, XTAV (1902), 1902. C239

[7] A. J. Echevarria. After Clausewitz: German military thinkers before the Great War. University Press of Kansas, Lawrence, KS, USA, 2001. C238

[8] J. A. English and B. I. Gudmundsson. On infantry. Praeger, Westport, CT, USA, 1994. C238

[9] B. A. Fiske. American Naval Policy. U.S. Naval Institute Proceedings, January 1905. C239

[10] L. Freedman. The official history of the Falklands Campaign, Volume 2: War and diplomacy. Routledge, London, 2005. C240, C243

[11] G. Fremont-Barnes. The Falklands 1982: Ground operations in the South Atlantic. Osprey, Oxford, UK, 2012.

https://ospreypublishing.com/the-falklands-2130 C240, C243, C248

[12] S. Fitz-Gibbon. Not mentioned in despatches: The history and mythology of the Battle of Goose Green. The Lutterworth Press, Cambridge, UK, 1995. http:

//www. lutterworth.com/product_info.php/products_id/1019 C240, C243

[13] T. R. Hogan. No shells, no attack! The use of fire support by three Commando Brigade Royal Marines during the 1982 Falkland Islands 
War. AD-A208862, US Army War College, PA, USA, 1989.

http://www.dtic.mil/dtic/tr/fulltext/u2/a208862.pdf. C240, $\mathrm{C} 248$

[14] L. R. Kosowski, A. Pincombe and B. Pincombe. Irrelevance of the fractal dimension term in the modified fractal attrition equation. ANZIAM J, 52:C988-C1011, 2011. doi:10.21914/anziamj.v52i0.3963 C236

[15] F. W. Lanchester. Aircraft in warfare: The dawn of the fourth arm. Constable, London, 1916.

https://archive.org/details/aircraftinwarfar00lancrich C239

[16] C. D. Landry. British artillery during Operation Corporate. Masters Thesis, United States Marine Corps Command and Staff College, 2002. http://www.dtic.mil/dtic/tr/fulltext/u2/a401278.pdf. C240, $\mathrm{C} 248$

[17] T. W. Lucas and T. Türkeş. Fitting Lanchester equations to the Battles of Kursk and Ardennes. Nav. Res. Log., 51:95-116, 2004. doi:10.1002/nav.10101 C236, C240, C241

[18] J. Millikan, M. Wong and D. Grieger. Suppression of dismounted soldiers: Towards improving dynamic threat assessment in closed loop combat simulations. In J. Piantadosi, R. S. Anderssen and J. Boland (eds), MODSIM2013, 1054-1060, 2013. http://www.mssanz.org.au/modsim2013/D1/millikan.pdf C237

[19] M. Osipov. The influence of the numerical strength of engaged forces in their casualties. Translated by R. L. Helmbold and A. S. Rehm. Nav. Res. Log., 42:435-490, 1995. doi:10.1002/15206750(199504)42:3<435::AID-NAV3220420308>3.0.CO;2-2 C239, $\mathrm{C} 240$

[20] R. Peterson. On the logarithmic law of combat and its application to tank combat. Oper. Res., 15:557-558, 1967. doi:10.1287/opre.15.3.557 C239 
[21] A. H. Pincombe and B. M. Pincombe. Markov modelling of the effectiveness of arms sanctions: A case study of the Falklands War. ANZIAM J., 48:C527-C541, 2006. doi:10.21914/anziamj.v48i0.80 C240

[22] A. H. Pincombe and B. M. Pincombe. Tractable approximations to multistage decisions in air defence scenarios. ANZIAM J., 49:C273-C288, 2007. doi:10.21914/anziamj.v49i0.349 C240

[23] A. H. Pincombe, B. M. Pincombe and C. E. M. Pearce. Putting the art before the force. ANZIAM J., 51:C482-C496, 2010. doi:10.21914/anziamj.v51i0.2584. C236, C237, C240, C241, C246

[24] A. H. Pincombe, B. M. Pincombe and C. E. M. Pearce. A simple battle model with explanatory power. ANZIAM J., 51:C497-C511, 2010. doi:10.21914/anziamj.v51i0.2585 C237, C240, C241, C246

[25] A. H. Pincombe and B. M. Pincombe. Dispersed combat as many-on-many search: Solving generalised Lanchester equations. ANZIAM J. to appear. doi:10.21914/anziamj.v57i0.10447 C237, C248

[26] B. M. Pincombe and A. H. Pincombe. Scoping a flexible deployment framework using adversarial scenario analysis. Int. J. Intell. Def. Supp. Sys., 3(3/4):225-262, 2010. doi:10.1504/IJIDSS.2010.037092 C240

[27] B. M. Pincombe, S. Blunden, A. H. Pincombe and P. Dexter.

Ascertaining a hierarchy of dimensions from time-poor experts: Linking tactical vignettes to strategic scenarios. Technol. Forecast. Soc., 80(4):584-598, 2013. doi:10.1016/j.techfore.2012.05.001 C240

[28] R. H. Scales. Firepower in limited war. National Defense University Press, Washington, DC, 1993. C240

[29] G. Smith. Battle atlas of the Falklands War 1982 by Land, Sea, and Air. Naval-History.net, Penarth, UK, 2006.

http://www naval-history.net/NAVAL1982FALKLANDS.htm C240, C243, C248 
[30] G. Hubbard. HMS Yarmouth: Captains Diary. http://www.hms-yarmouth.com/co.diary.htm. C240, C248

\section{Author addresses}

1. B. M. Pincombe, LCA, JOAD, DST Group, Australia. mailto:brandon. pincombe@dsto. defence.gov . au orcid:0000-0003-3560-7497

2. A. H. Pincombe, Pincombe Consulting, Australia. mailto:adrianpincombe@gmail.com 